\title{
Innovative chemotherapeutical treatment options for alveolar and cystic echinococcosis
}

\author{
A. HEMPHILL ${ }^{1 *}$, M. SPICHER ${ }^{1}$, B. STADELMANN ${ }^{1}$, J. MUELLER ${ }^{1}$, \\ A. NAGULESWARAN ${ }^{2}$, B. GOTTSTEIN ${ }^{1}$ and M. WALKER K $^{3}$ : \\ ${ }^{1}$ Institute of Parasitology, University of Berne, Länggass-Strasse 122, CH-3012 Berne, Switzerland \\ ${ }^{2}$ Department of Pharmacology and Toxicology, Indiana University School of Medicine, 635 Barnhill Drive, \\ MS A-515, Indianapolis, IN 46202, USA \\ ${ }^{3}$ Department of Medicine, Harvard School of Public Health, Boston, MA 02115, USA
}

(Received 3 Fune 2007; revised 3 Fune 2007; accepted 4 Fune 2007; first published online 16 Fuly 2007)

\begin{abstract}
SUMMARY
Echinococcus granulosus and Echinococcus multilocularis are cestode parasites, of which the metacestode (larval) stages cause the diseases cystic echinococcosis (CE) and alveolar echinococcosis (AE), respectively. Albendazole and mebendazole are presently used for chemotherapeutical treatment. However, these benzimidazoles do not appear to be parasiticidal in vivo against $\mathrm{AE}$. In addition, failures in drug treatments as well as the occurrence of side-effects have been reported. New drugs are needed to cure $\mathrm{AE}$ and $\mathrm{CE}$, which are considered to be neglected diseases. Strategies currently being implemented to identify novel chemotherapeutical treatment options include (i) conventional primary in vitro testing of broad-spectrum anti-infective drugs, either in parallel with, or followed by, animal experimentation; (ii) studies of drugs which interfere with the proliferation of cancer cells and of Echinococcus metacestodes; (iii) exploitation of the similarities between the parasite and mammalian signalling machineries, with a special focus on targeting specific signalling receptors; (iv) in silico approaches, employing the current Echinococcus genomic database information to search for suitable targets for compounds with known modes of action. In the present article, we review the efforts toward obtaining better anti-parasitic compounds which have been undertaken to improve chemotherapeutical treatment of echinococcosis, and summarize the achievements in the field of host-parasite interactions which may also lead to new immuno-therapeutical options.
\end{abstract}

Key words: cystic echinococcosis (CE), alveolar echinococcosis (AE), chemotherapy, immunotherapy, signalling, drugs, host-parasite interactions.

\section{ECHINOCOCCUS AND ECHINOCOCCOSIS}

Echinococcosis, caused by the larval stages of the cestode parasite of the genus Echinococcus, is a lifethreatening disease of serious public health and economic concern of global proportion (Torgerson, 2003; Eckert and Deplazes, 2004). Four distinct species within the genus Echinococcus have been identified i.e. Echinococcus multilocularis, E. granulosus, E. vogeli and E. oligarthrus (Thompson, 1986). All Echinococcus species are potentially zoonotic, but only 2 are of significant medical importance in humans: E. multlilocularis (small fox tapeworm) being the most pathogenic parasite, and E. granulosus (dog tapeworm) being the commonest (Rausch, 1995; McManus et al. 2003).

* Corresponding author: Institute of Parasitology, Vetsuisse Faculty, University of Berne, Länggass-Strasse 122, CH-3012 Berne, Switzerland. Tel: +41316312384. Fax: +41316312477. E-mail: hemphill@ipa.unibe.ch $\$$ Current address: Swiss Veterinary Office, Schwarzenburgstrasse 155, CH-3000 Berne, Switzerland.
E. multilocularis infection causes alveolar echinococcosis (AE) in intermediate hosts (rodents) and humans, and is restricted to the northern hemisphere. In contrast, E. granulosus, the causative agent of cystic echinococcosis (CE) that occurs worldwide (Schantz et al. 1995). The habitat of the adult worms is the small intestine of their respective definitive host (canids for E. granulosus, and canids and felids for E. multilocularis), where sexual reproduction and subsequent egg production take place. Eggs released in the faeces into the environment, where they are accidentally ingested by suitable intermediate hosts, such as small rodents for E. multilocularis, and mainly livestock for E. granulosus. Humans represent an aberrant intermediate host, acquiring the disease through the accidental ingestion of eggs, with serious consequences. Each egg contains an oncosphere (=first larval stage), which actively penetrates the intestinal lining and is transported via the blood and lymph to the sites of predilection/ establishment. Affected organs in humans are mainly the liver for E. multilocularis and the liver and 


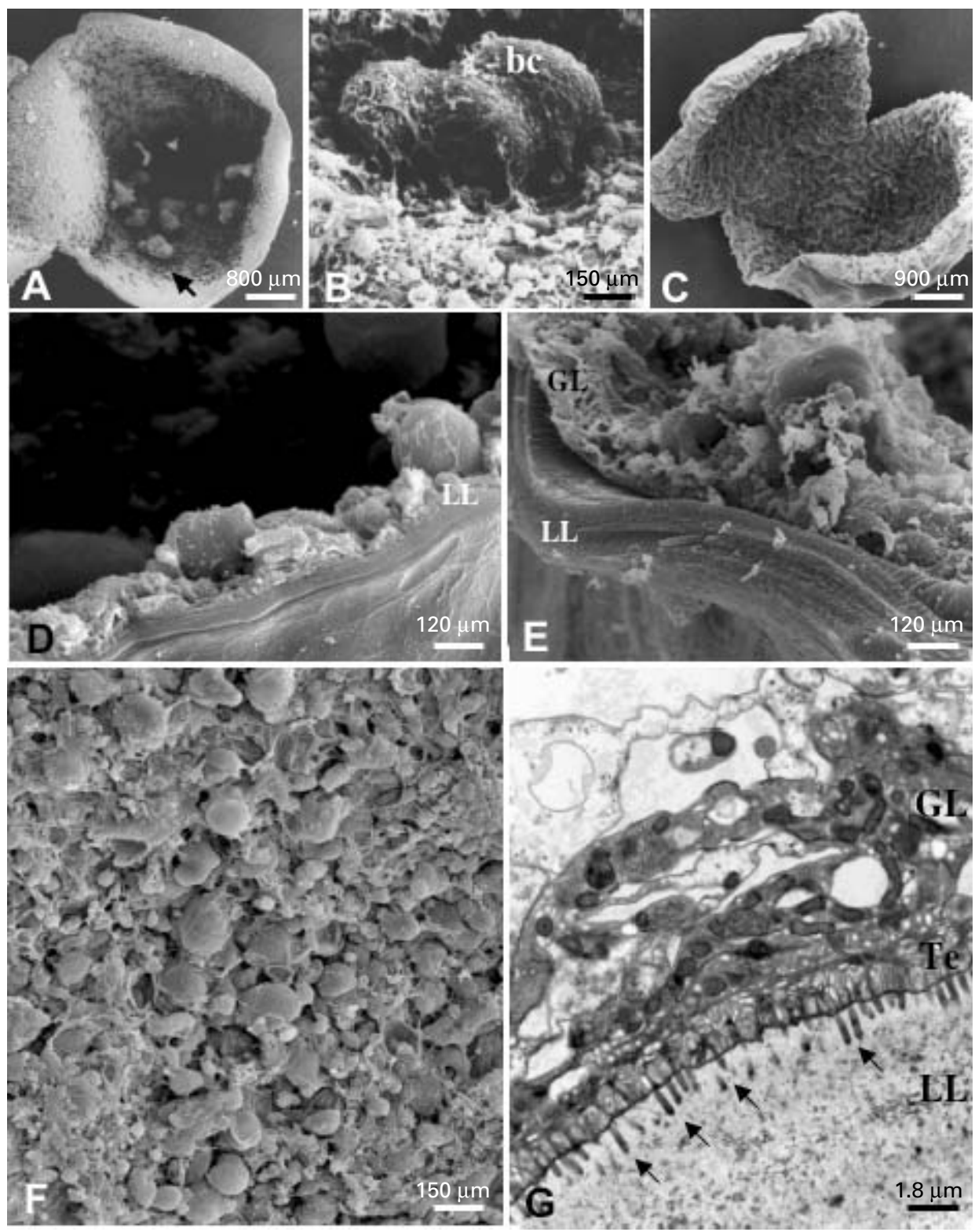

Fig. 1. Morphology and ultrastructure of Echinococcus metacestodes. (A) E. multilocularis metacestode, cut open to view the germinal layer with developing brood capsules (arrow); (B) SEM of brood capsules (bc) containing developing protoscoleces; (C) E. granulosus metacestode cultured in vitro; (D) SEM showing laminated layer and germinal layer of E. multilocularis metacestode; (E) SEM of laminated layer and germinal layer of E. granulosus metacestode; (F) SEM of germinal layer-associated tissue of E. multilocularis; (G) TEM of E. granulosus metacestodes showing laminated layer, tegument and germinal layer. $\mathrm{GL}=$ germinal layer, $\mathrm{LL}=$ laminated layer, $\mathrm{Te}=$ tegument, arrows in $(\mathrm{G})$ point towards microtriches.

lung in the case of E. granulosus. In these sites, the oncospheres develop into metacestodes (= second larval stage). Within these metacestodes, via asexual reproduction, brood capsules and protoscoleces form in natural intermediate hosts. If the metacestode in/ from an infected intermediate host is ingested by a suitable definitive host, the life-cycle is concluded. Protoscolex development in humans has only rarely been described (Gottstein and Hemphill, 1997).

Metacestodes represent the disease-causing stage. They are fluid-filled cysts with cellular and acellular compartments (Fig. 1). The outer, acellular surface of the metacestode is formed by the laminated layer, a carbohydrate-rich structure, synthesized by the parasite, which, in terms of thickness, is much more prominent in E. granulosus than E. multilocularis metacestodes (Gottstein and Hemphill, 1997). In addition, E. granulosus metacestodes are surrounded by a very prominent host-derived fibrous capsule, the adventitial layer, which is composed of host connective tissue. The laminated layer plays a crucial role in the survival strategy of the parasite by modulating immunological and physiological reactions of the host (Gottstein et al. 2002; reviewed 
in Siles-Lucas and Hemphill, 2002). The actual larval tissue is formed by the germinal layer, the distal part of which consists of the tegument which is directly associated with the inner surface of the laminated layer. The tegument is characterized by microvilli-like extensions termed microtriches, which protrude well into the matrix of the laminated layer and increase the resorbing surface of the parasite. In addition, the germinal layer contains highly differentiated cell types, including connective tissue, muscle cells, glycogen storage cells and many undifferentiated cells (Eckert et al. 1983).

Typically, the fully mature E. granulosus metacestode (i.e. hydatid cyst) is a single-chambered or septated but usually unilocular cyst, which displays expansive growth, causing a compression of neighbouring tissue and resulting in organ dysfunction and disease (Kern, 2003, 2006). In E. multilocularis infection, the metacestode represents a multivesicular structure which reproduces (also asexually) by exogenous formation and budding of daughter vesicles, which resembles progressive tumour-like growth (Ohbayashi et al. 1971; Ali-Kahn et al. 1983). This growth leads to the a large and heterogenous mass of the parasite characterized by mostly peripheral actively proliferating areas and, in many cases, centrally located necrotic tissue. Metastases can occur in other organs following the release of germinal layer cells into the blood or lymph system (Ali-Kahn et al. 1983; Eckert et al. 1983; Mehlhorn et al. 1983).

LIMITATIONS OF CURRENT

CHEMOTHERAPEUTICAL TREATMENT

Traditionally, the treatment of echinococcosis relies primarily on surgery and/or chemotherapy, and the treatment strategy depends largely on different factors, such as metacestode size and location, viability status, the interaction between the expanding parasite and the adjacent host tissue, complicating bacterial or fungal infection and potential complications related to cyst rupture and spillage of protoscoleces (Kern, 2003, 2006).

In $\mathrm{CE}$, radical resection of the cyst mass represents the traditional treatment strategy and is, in many instances, accompanied by chemotherapy prior to and following surgery. Protoscolicidal substances are often applied, since there is a risk of spillage of cyst fluid containing protoscoleces, which can lead to metastases (Stey and Jost, 1993; Pawloski, 1997; Kern, 2003, 2006). PAIR (puncture, aspiration, injection, re-aspiration) is a technique that was introduced in the mid-eighties, and includes percutaneous puncture of the cysts under ultrasonic guidance, aspiration of substantial amounts of cyst fluid, injection of protoscolicidal substance (e.g. $95 \%$ ethanol), and re-aspiration of the fluid cyst content after 15-20 min. Although the efficacy and potential risks have not been fully evaluated, and more long-term studies are needed, PAIR has been used in several hundred patients (Eckert and Deplazes, 2004; Brunetti et al. 2004). For inoperable cases, chemotherapy applying benzimidazoles is the only option. There are over 2000 well-documented inoperable cases of $\mathrm{CE}$, which have undergone treatment with benzimidazoles. When evaluated up to 12 months after initiation of chemotherapy, cysts disappeared in $30 \%$ of patients, cysts degenerated in $50-70 \%$, indicating improvement, and in $20-30 \%$ of patients E. granulosus metacestodes did not respond to chemotherapy (Pawloski et al. 2001). Praziquantel (PZQ), a heterocyclic pyrazinoisoquinoline derivative has been proposed for use together with benzimidazoles in CE patients. PZQ exhibits a high efficacy against protoscoleces and metacestodes in animal experiments (Urrea-Paris et al. 1999, 2001), and the combined treatment with $\mathrm{ABZ}$ and $\mathrm{PZQ}$ given during the month prior to surgery has been shown to increase the number of human patients with nonviable protoscoleces as compared to therapy with ABZ alone (Cobo et al. 1998).

For the treatment of AE, surgery, if applicable, is accompanied by chemotherapy using benzimidazoles, which should be maintained for at least 2 years following surgery, and the monitoring of patients should be continued for 10 years (Pawloski et al. 2001). Inoperable AE cases must undergo longterm, often life-long, chemotherapy with albendazole (ABZ) and/or mebendazole (MBZ) (Reuter et al. 2000, 2004). Extensive animal experimentation and observations in human patients sufferering from $\mathrm{AE}$ have demonstrated that ABZ and MBZ exhibit a parasitostatic rather than a parasitocidal effect (El-On, 2002; Reuter et al. 2004). Thus, benzimidazoles only prevent $E$. multilocularis growth, and the recurrence rates after interruption of therapy are high. Nevertheless, clinical studies have shown that chemotherapy has significantly increased the 10 -year survival rate of inoperable or non-radically operated AE patients from $6-25 \%$ to $80-83 \%$ (Ammann and Eckert, 1995. Eckert and Deplazes, 2004). Spontaneous cure of AE, leading to calcified lesions is possible, but it is not known how frequently calcification occurs (reviewed by Gottstein and Hemphill, 1997; Vuitton et al. 2006). Large surveys in endemic areas have shown that the number of patients with established AE is considerably lower than the number of seropositive humans exposed to the eggs of E. multilocularis (see Rausch et al. 1987; Bresson-Hadni et al. 1994; Bartholomot et al. 2002). This information suggests that immunity in humans is capable of killing the parasite after infection, which could facilitate the development of immunotherapeutical tools.

The clinical application of benzimidazoles for the treatment of $\mathrm{AE}$ and $\mathrm{CE}$ was accompanied by studies 
employing animal models, focusing on comparing the activities of different benzimidazole derivatives, and on different formulations and modes of application. The efficacies of oral administration were demonstrated to be dependent on the duration of treatment and the age of the parasite. Efficacy increases with the duration of treatment, but is decreased for infections which have persisted for long periods of time (over 6 months in mice) (Wangoo et al. 1987). Increasing doses produced better results, although clear parasitocidal effects were not achieved (Taylor et al. 1989), and observations consistent with drug resistance were described (Morris and Taylor, 1990). There are conflicting reports of the most suitable mode of administration of benzimidazoles. It was postulated that parenteral administration of benzimidazoles resulted in a higher efficacy than other routes in animals experimentally infected with E. multilocularis (reviewed by SilesLucas and Hemphill, 2002). Drug combinations, normally consisting of one benzimidazole and one or more other compound, were tested in order to obtain better treatment efficacies. For instance, synergistic effects were reported for combinations of ABZ with the dipeptide methyl ester Phe-Phe-OMe (Sarciron et al. 1997). In addition, novel formulations of benzimidazoles, either as pro-drugs (Walchshofer et al. 1990), liposome-entrapped compounds (Wen et al. 1996) or colloidal, intravenously injectable formulations (Rodrigues et al. 1995) were tested in rodents and showed enhanced efficacy at lower doses than the parental compounds. However, these studies have not yet been translated into clinical applications, with one exception: Chai et al. (2004) reported on improved efficacy of ABZ emulsion compared with ABZ tablets or capsules for the treatment of liver CE.

Adverse reactions against benzimidazoles under long-term chemotherapy include elevation of transaminases, proteinuria, hair loss, gastrointestinal disturbances, neurological symptoms (vertigo/dizziness), leukopaenia, headache, abnormal liver biopsy, abdominal pain, fever, urticaria, thrombocytopaenia, allergic shock (due to cyst collapse and release of E. granulosus cyst fluid) and toxicity to bone marrow. A study comprised of 3282 echinococcosis patients treated with ABZ showed that most side-effects were associated with the gastrointestinal tract (Pawloski, 1997; Kern, 2003), but no fatal cases involving ABZ therapy have been described. In $3 \cdot 8 \%$ of these cases, permanent discontinuation of treatment had to be undertaken. As suggested by animal experimentation (Horton, 1989, 1997), MBZ and ABZ may induce embryotoxic or teratogenic effects, and it is recommended that these drugs are not used for the treatment of pregnant women. Constant monitoring of drug levels in serum is suggested in order to prevent toxic reactions.
TOWARDS THE DEVELOPMENT OF IMMUNOTHERAPEUTICAL APPROACHES FOR THE TREATMENT OF ECHINOCOCCOSIS

Considerable effort has gone into elucidating the immunological basis of the host-parasite relationship during infection with Echinococcus. In both $\mathrm{AE}$ and $\mathrm{CE}$, the initial immune responses during the primary phases of infection are characterized by a predominantly Th1-type response, whereas in the later stages of disease progression, the immune response switches to a Th2 polarized profile (Gottstein et al. 2006; Vuitton et al. 2006; Zhang and McManus, 2006). In addition, one of the hallmarks of most helminth infections is the occurrence of a profound immuno-modulation and -suppression (Maizels and Yazdanbakhsh, 2003). Hence, E. granulosus and E. multilocularis have a significant influence on the immune response in their hosts. For both E. multilocularis and E. granulosus, it has been shown that carbohydrate moieties or carbohydraterich fractions possess immunomodulatory properties (Dai et al. 2001; Dematteis et al. 2001; Walker et al. $2004 a$; reviewed by $\mathrm{Baz}$ et al. 2006). This information is in accordance with findings of studies investigating the involvement of glycans in immunomodulation during helminth infections (Maizels and Yazdanbakhsh, 2003), and the current challenge is to translate this knowledge into novel immuno-therapeutical applications.

\section{Cystic echinococcosis}

Some insights into the initial phases of CE have been obtained using experimental E. granulosus infection in sheep or mice (Baz et al. 2006; Zhang and McManus, 2006). The initial low-level Th1-biased immune response following the infection is accompanied by an infiltration of macrophages and eosinophils and the development of a weak humoral immune response. Conversely, established cysts in experimentally infected animals and in human patients are capable of modulating the immune response, resulting in a Th2-polarized profile exhibiting the production of IL-4, IL-5, IL-6 and IL-10 and balanced by Th1 cytokines, such as IFN- $\gamma$. Upon the death of an E. granulosus cyst either naturally or due to chemotherapy, levels of Th2 cytokines decrease rapidly and the immune response polarizes towards Th1; upon relapse, Th2 responses regenerate within a few weeks. This Th1$\mathrm{Th} 2$ co-existence and inter-conversion during $\mathrm{CE}$ is likely to be mediated by $E$. granulosus antigens. Examples of antigens which bear epitopes which can induce both Th1 and Th2 responses are Eg2HSP70, EgA31 and Eg/Trp, (Ortona et al. 2003; Fraize et al. 2005). Another efficient strategy which contributes to the parasite survival strategy is the disruption of effector mechanisms of the host immune repsonse. In a study of E. granulosus, Diaz and co-workers 
showed that the activation of complement is inhibited by the binding of the host inhibitory Factor $\mathrm{H}$ to the hydatid cyst wall. The same authors investigated the consumption of complement components by molecular factors within the hydatid cysts (Diaz et al. 1999; Ferreira et al. 2000, 2001). In addition, $\mathrm{T}$ cell responses were shown to be modulated by the intensity of infection, as demonstrated in mice infected with different doses of E. granulosus protoscoleces (Dematteis et al. 2003). The generation of $\mathrm{T}$ cell lines from patients exhibiting different courses of disease (harbouring active, transitional or inactive cysts) and subsequent stimulation of these cells with hydatid fluid and/?or? a defined E. granulosus antigen $(\mathrm{AgB})$ has also shown that Th1 cells contribute to the inactive stage of hydatid disease, whereas Th2 cells have been shown to be more important in the active and transitional stages (Rigano et al. 2004). Interestingly, patients undergoing chemotherapy with benzimidazoles exhibited a more pronounced Th1 cytokine profile, reflecting the regression of the metacestode (Rigano et al. 1995). Self cure of CE, leading to calcified cysts, is common in sheep and also in the human population in hyperendemic regions (MacPherson et al. 2004 ; Moro et al. 2005), and cytokines are likely to play a key role in these processes. Elucidating the factors involved in cyst calcification could lead to novel therapeutical approaches.

\section{Alveolar echinococcosis (AE)}

In accordance with $E$. granulosus infection in humans, Th1 responses dominate the early stages of E. multilocularis infection, with the immune response switching to Th2 at the chronic stage of disease (Zhang and McManus, 2006). Antibody levels are low initially, but levels of IgG1 and IgG3 increase during infection. In human patients, a strong cellular immune response is a characteristic hallmark, resulting in granulomatous infiltrate surrounding the parasite lesions (Vuitton et al. 1989; Grenard et al. 2001). In patients with abortive or dead lesions, the cells contributing to this granuloma formation are mostly macrophages, myofibroblasts and a large number of CD $4+\mathrm{T}$ cells, and in patients exhibiting a progressive clinical course of $\mathrm{AE}$, there is an increased number of CD8 $+\mathrm{T}$ cells (Manfras et al. 2002). This corresponds to findings in mice, which have shown that E. multilocularis metacestodes exhibit a considerably increased growth in nude, TCR- $\beta(-/-)$ and MHC-II $(-/-)$ mice compared with wild type $\mathrm{C} 57 \mathrm{BL} / 6$ mice, with the T cell-deficient mice dying 2 months after infection (Dai et al. 2004). Thus, CD $4+\alpha \beta+\mathrm{T}$ cells play a growth-limiting role in $E$. multilocularis infection.

A further hallmark of $\mathrm{AE}$ is the development of fibrosis surrounding the parasite. In human patients, fibrotic processes are frequently observed, even distant from the lesions caused by the parasite, suggesting a major role for cytokines in collagen synthesis and cross-linking (Vuitton et al. 2006). There are indications that fibrotic processes might be directed by the parasite itself. A parasite trans-glutaminase has been shown to be strongly expressed in and at the border of metacestodes, and this enzyme was capable of cross-linking human collagen in vitro (Grenard et al. 2001). Fibrosis itself, in addition to the outer acellular laminated layer, could be responsible for keeping cytolytic immune cells away from the parasite tissue.

The observation that a strong cellular immunity renders mice less susceptible to disease and that Th1 type immune responses, as assessed by corresponding cytokines, may kill the parasite or prevent its development suggests that immuno-therapeutical tools could be developed to combat echinococcosis. This notion is supported by evidence that the stimulation of the immune system with Bacille Calmette Guerin (BCG) has been reported to exhibit a profound reductive effect on the size and dissemination of $E$. multilocularis metacestodes in rodents (Rau and Tanner, 1975). However, despite encouraging clinical results, there are no reports on the limited BCG-trials in human patients (Vuitton et al. 2006).

Another immuno-stimulating compound, Isoprinosine $^{\mathrm{TM}}$, has been shown to have a good efficacy against E. granulosus and E. multilocularis metacestodes and protoscoleces in vitro as well as in mice and jirds (Sarciron et al. 1992, 1993, 1995 ; Lawton et al. 2001). The drug has been applied in patients with $\mathrm{AE}$, and has shown a regression of parasite lesions in 2 patients (reviewed by Vuitton et al. 2006). This compound acts through stimulating cellular immunity, increasing IL-1, IL-2 and IFN$\gamma$-production, and inhibiting Th2 type immune responses, including IgE-dependent reactions.

The pre-treatment of mice with IL-12 has been shown to efficiently limit the development of parasite lesions, resulting in aborted metacestode vesicles surrounded by infiltrative cells and fibrosis (Emery et al. 1998). However, IL-12 treatment has not been evaluated as a therapeutic agent in human $\mathrm{AE}$ patients because of potential side-effects.

Liance et al. (1998) reported that the in vivo treatment of mice with a low dose $(1 \mu \mathrm{g}$, twice a week for 3 weeks) of IFN- $\gamma$ decreased metacestode growth and liver fibrogenesis. The effect was dosedependent, as the treatment with a higher dose $(5 \mu \mathrm{g}$, twice a week for 3 weeks) increased the number of metacestodes in the liver. Two case reports documented the clinical efficacy of IFN- $\gamma$-treatment. One patient suffering from severe side-effects caused by $\mathrm{ABZ}$-therapy was treated with IFN- $\gamma$ during a 3 -day period once a month, and this treatment prevented disease progression but did not alter the Th2dominated immune response against this parasite 
(Jenne et al. 1998). Another patient whose lesions were growing, despite mebendazole therapy, was treated with a combination of IFN- $\gamma$ and mebendazole, which halted the progression of disease as revealed in a 1-year follow-up period (Schmid et al. 1995).

The treatment of mice with IFN- $\alpha-2 \mathrm{a}$ has been shown to largely prevent the formation of hepatic lesions in infected mice, with an inhibition of IL-10, IL-6 and IL-13 antigen-induced secretion in spleen cell cultures (Godot et al. 2003). One patient with $\mathrm{AE}$ and chronic hepatitis $\mathrm{C}$ was treated effectively with IFN- $\alpha-2$ a, suggesting that this cytokine limited parasite growth and reversed the cytokine profile to Th1 (Harraga et al. 1999). Thus, IFN $\alpha$-2a seems to be the most promising candidate for, for instance, further clinical investigation, because it is already widely used for treating chronic viral infections. However, more studies are required to assess the ambiguous role of this cytokine.

SEARCHING FOR NOVEL CHEMOTHERAPEUTICAL OPTIONS

As discussed, novel and improved therapeutical tools are needed in order to optimize treatment of $\mathrm{CE}$ and $\mathrm{AE}$. Both in vitro and in vivo laboratory models have been used for drug evaluation (reviewed by Siles-Lucas and Hemphill, 2002). Unfortunately, besides the initial development of benzimidazoles, the pharmaceutical industry has not expressed a keen interest in supporting the discovery of novel treatment options. Therefore, $\mathrm{AE}$ and $\mathrm{CE}$ must be regarded as neglected diseases.

Historically, the primary assessment of antiechinococcal drug candidates has often been performed in rodents (mice or gerbils), which has led to the extensive use of animal experimentation. Subsequently, the in vitro culture of Echinococcus metacestodes has proven to be a suitable tool for the primary assessment of parasite susceptibility to certain compounds, with a focus on broad-spectrum anti-infective agents, and also represents an ideal model system for studies on drug uptake and associated metabolic changes imposed upon the parasite (Hemphill et al. 2002). More recently, optimized in vitro culture conditions (Spiliotis et al. 2004) have allowed the dissection of the molecular nature of the signalling machinery within $E$. multilocularis metacestodes required for communication at the host-parasite interface (reviewed by Brehm et al. 2006). These studies have provided extensive information on novel potential drug targets associated with the parasite signalling network. Although the availability of genomics and related technologies provides avenues for the application of modern approaches, the current genomic and expressed sequence tag (EST) information on Echinococcus is still limited. Nonetheless, the generation of more
EST data is underway (see http://www.sanger. ac.uk/Projects/Echinococcus/) and will be an extremely valuable resource for gene expression studies.

The following strategies are currently being followed in order to identify novel alternative chemotherapeutical treatment options: (i) conventional primary in vitro testing of broad-spectrum anti-infective drugs, either in parallel with, or followed by, animal experimentation; (ii) studies on drugs which interfere with the uncontrolled proliferation of cancer cells and affect the viability of Echinococcus metacestodes and protoscoleces; (iii) exploitation of the similarities between the parasite and mammalian signalling machineries, with a special focus on targeting specific signalling receptors; (iv) in silico approaches, employing the current Echinococcus genomic database information to search for suitable targets for compounds of known mode of action.

\section{(i) Chemotherapeutical activities of anti-infective drugs}

In vitro chemotherapy studies of $\mathrm{CE}$ have mostly, but not exclusively, focused on protoscoleces, since these are easily cultured, and their differentiation into metacestodes is a time-consuming process that can easily take 4-6 months (Walker et al. 2004b). Experimental prophylactic therapy of E. granulosus protoscoleces was carried out as a model that would mimic spillage during surgery, by treating protoscoleces with PZQ (Urrea-Paris et al. 2001) or a combination of PZQ and ABZ (Casado et al. 2001) prior to injection into mice. Respective findings are of substantial clinical relevance. Other promising compounds with in vitro protoscolicidal actions were cetrimide (Frayha et al. 1981) and the ionophore monensin (Rogan and Richards, 1986), but these drugs were found to be rather ineffective against metacestodes. Levamisole and ivermectin, which are classically nematocidal, were shown to exhibit in vitro activities similar to benzimidazoles (Martinez et al. 1999). Against E. granulosus infection in rodents, a combination of fenbendazol and netobimin (Garcia-Llamarez et al. 1997) showed synergistic effects, allowing the administration of lower drug dosages. Oxfendazole, like ABZ, is a benzimidazole, used in veterinary medicine for the treatment of nematode infections, and has a similar antimicrobial spectrum but a longer half-life. Experimental treatments of naturally E. granulosus-infected sheep and goats suggested that oxfendazole may be as efficacious as ABZ, but does not require daily uptake of the drug because of its prolonged bioavailability (Blanton et al. 1998; Dueger et al. 1999). Xiao et al. (1995) studied the effects of several drugs on enzymes involved in carbohydrate metabolism and found that some of the corresponding host enzymes 
were not affected, thus identifying novel potential drug targets. Cyclosporin A, employed mainly as an immunosuppressant during the management of organ transplants, also exhibits anti-echinococcal activity. While the administration of cyclosporin $A$ in 5 consecutive daily doses, beginning 2 days prior to the infection of mice with E. granulosus protsocoleces, resulted in a significant reduction in cyst numbers and cyst masses measured at 20 weeks after infection; no changes in cyst mass and numbers were recorded when the drug was administered 18 weeks after infection, but the wet weight was decreased by $42 \%$ compared with untreated controls. Ultrastructural examination of the germinal membrane and laminated layer of late-treated E. granulosus revealed abnormalities in all cysts studied, whereas control and early-treated hydatids were normal (Hurd et al. 1993).

In rodents infected with $E$. multilocularis metacestodes, mytomicin $\mathrm{C}$, piperazine and quinolone derivates, alkylaminoethers and propargylic alcohols exhibited parasitostatic effects, at either a lower or comparable level as benzimidazoles (reviewed by Siles-Lucas and Hemphill, 2002). PZQ has been used for the treatment of $\mathrm{AE}$, but experimental data in animals have shown that the efficacy of PZQ against E. multilocularis metacestodes was inadequate (Marchiondo et al. 1994). Also, the treatment of $E$. multilocularis-infected mice with alphadifluoromethylornithine was not successful (Miyaji et al. 1993). In contrast to its use against CE, cyclosporin A did not have any anti-parasitic activity against $E$. multilocularis infection in experimentally infected mice, and its immunosuppressive activity was shown to be more effective than its parasitostatic effect (Liance et al. 1992).

Nitazoxanide (NTZ), a broad-spectrum anthelminthic also used for treatment against enteric bacteria, Giardia and Cryptosporidium (cf. Hemphill et al. 2006), was identified as a compound inducing significant distortion of the germinal layer in vitro, and NTZ-treated E. multilocularis metacestodes were non-viable when introduced into susceptible mice (Stettler et al. 2003). NTZ was also found to induce severe damage to E. granulosus protoscoleces and the germinal layer of in vitro-cultured E. granulosus metacestodes (Walker et al. 2004b). NTZ represents the parent compound of a class of drugs named thiazolides, which include modified variants of NTZ (Hemphill et al. 2006; Esposito et al. 2007). In vitro studies of E. multilocularis and E. granulosus employing NTZ-derivatives have shown that metacestodical and protoscolicidal activities of this class of drugs strongly depend on the presence of the nitro-thiazole moiety, suggesting that this nitro-group is instrumental for the activity of thiazoldies (Naguleswaran and Hemphill, unpublished findings). These promising results indicate the potential of NTZ and possibly other thiazolides as novel anti-echincoccocal compounds (Craig, 2003).

Recently, Reuter et al. (2006) investigated the efficacy of a series of compounds against E. multilocularis metacestodes, including ABZ, artemether, caspofungin, itraconazole (ITZ), ivermectin, methiazole (MTZ), miltefosine, NTZ, rifampicin and trimethoprim/sulfamethoxazole. They found that ABZ, ITZ, MTZ and NTZ effectively destroyed parasite vesicles in vitro. However, after drug discontinuation, re-growth of vesicles occurred, indicating a parasitostatic effect only. Combination treatment with ABZ/NTZ at concentrations between 1 and $10 \mu \mathrm{g} / \mathrm{ml}$ for 3 weeks yielded no re-growth of parasites during 8 months of drug discontinuation, and the subsequent evaluation in a bioassay in gerbils did also not result in viable parasite infections. These results indicated that combined ABZ/NTZ treatment exhibits a parasitocidal effect. In this respect, Stettler et al. (2004) have shown that NTZ, applied orally to E. multilocularis-infected mice, either alone or in combination with ABZ, exhibited a profound anti-parasitic efficacy, with the ABZ/NTZ combination yielding the most promising outcome. Electron microscopical analysis of metacestode tissue obtained from treated mice suggested that the ABZ/NTZ combination exerted a synergistic effect. However, the pharmacokinetic analysis of corresponding serum levels in mice showed that the application of ABZ in combination with NTZ increased considerably the ABZSO-levels and also the half-life of ABZSO (Stettler et al. 2004). Therefore, the increased efficacy observed in mice could be the result of both direct effects of NTZ and ABZ metabolites and increased availability of ABZSO in mice receiving the combination treatment.

Amphotericin B desoxycholate (cAMB), an antifungal compound, was shown to effectively inhibit the growth of E. multilocularis metacestodes in vitro and in human patients in vivo (Reuter et al. $2003 a, b)$. A major limitation of cAMB is its mode of administration (intravenous), which makes it unsuitable for prolonged use, except for salvage treatment (Reuter et al. 2003b). Also, the effect of cAMB is only parasitostatic and the drug is nephrotoxic, limiting its widespread use. Nevertheless, prolonged application of CAMB for months to years may be feasible in some cases, as side-effects are mild and serious organ damage does not appear to occur (Reuter et al. 2003b).

\section{(ii) Anti-cancer drugs and echinococcosis}

There are a number of similarities between cancer cells and some parasites, particularly Echinococcus (reviewed by Klinkert and Heussler, 2006). Similarities include features, such as the essentially 
unlimited proliferative capacity of protoscoleces/ brood capsules, the potential to modulate the immune response, the secretion of proteolytic enzymes to reach their target sites or organs, and the formation of metastases. E. multilocularis metacestodes behave like malignant tumours, and there is an association between the uncontrolled proliferation and growth and the over-expression in metacestodes of a family of proteins named 14-3-3 (Siles-Lucas et al. 1998, 2001). 14-3-3 proteins are found in all eukaryotic cells and participate in protein kinase signalling pathways. They function as phosphoserine/phosphothreonine-binding modules and have an effect on phosphorylation-dependent events, such as DNA-damage checkpoints and prevention of apoptosis (reviewed by Siles-Lucas and Gottstein, 2003). Some 14-3-3 proteins have been found to be aberrantly expressed in tumour cells, acting either pro-or anti-tumourogenically. Indeed, when Echinococcus 14-3-3 sequences are aligned with other 14-3-3 isoforms of other organisms, those overexpressed in metacestodes can be grouped with the tumour-growth related zeta-isoforms (Siles-Lucas et al. 2001). This information suggests that certain anti-tumour agents could interfere with the growth of Echinococcus metacestodes.

Doxorubicin, or hydroxyldaunorubicin, is a DNA-interacting drug used widely in the treatment of a wide range of cancers (Launchbury and Habboubi, 1993). The parasiticidal properties of doxorubicin bound to polyisohexylcyanoacrylate nanoparticles (a colloidal biodegradable drug carrier) were assessed against the metacestode of E. multilocularis (see Liance et al. 1993). A reduction of the development of the parasite in the liver and a reduced viability of the metacestode were observed in mice injected with $5 \mathrm{mg} / \mathrm{kg}$ body weight, but $7.5 \mathrm{mg} / \mathrm{kg}$ body weight did not appear more efficient. Free doxorubicin or unbound nanoparticles had no anti-parasitic activity (Liance et al. 1993).

Another class of anti-cancer agents with proven anti-parasitic activities are isoflavonoids. Isoflavonoids are substances formed by plant tissue in response to physiological stimuli, such as infectious agents, with reported anti-oxidant, -bacterial, -viral and -fungal activities (Dakora and Philipps, 1996). They are composed of a characteristic 15-carbon backbone ring structure connected by a heterocyclic pyrane (3-C) bridge (C6-C3-C6) (Reynaud et al. 2005), with the 2 aromatic rings generally containing a number of phenolic hydroxyl groups. Genistein, a major component of soya, is the most prominent isoflavonoid, and inhibits growth and metastasis of a number of cancer cell lines (breast, prostate, skin and colon) (Messina, 1999). Genistein also stimulates the synthesis of TGF- $\beta$, which itself inhibits cancer cell proliferation (Messina, 1999). Besides other targets, genistein acts on a number of signalling pathways by functioning as a kinase inhibitor (tyrosine kinase, MAP kinase, ribosomal S6 kinase). Recent studies have shown that genistein is highly effective against E. multilocularis metacestodes in vitro (Naguleswaran et al. 2006). However, genistein has a disadvantage, in that it also exerts oestrogenic effects by binding to oestrogen receptor- $\beta$, which renders genistein unfavourable for long-term treatment. Binding to the oestrogen receptor- $\beta$ has been proven to take place through the hydroxyl-group associated with the B-ring of the molecule. Therefore, a number of isoflavonoids that do not carry this hydroxylgroup have been tested in vitro and do not meet the steric requirements to bind to the oestrogen receptor-beta. One of these compounds, Rm6423, exhibits a pronounced anti-parasitic activity against E. multilocularis metacestodes as well as against E. granulosus metacestodes and protoscoleces (Naguleswaran et al. 2006). Moreover, an examination of culture medium revealed increased leakage of parasite proteins into the medium during treatment, and zymography demonstrated a loss of the activity of metalloproteases. The molecular basis of the efficacy of genistein and its derivative Rm6423 has not yet been elucidated, but these compounds could interfere in signalling, for instance, through an inhibition of the tyrosine kinase activity associated with the epidermal growth factor receptor identified in E. multilocularis (see Spiliotis et al. 2006).

An endogenous metabolite of oestrogen with both anti-angiogenic and anti-tumour effects, 2-methoxyestradiol (2-ME) (reviewed by Schumacher and Neuhaus, 2001) has been shown to down-regulate the pro-tumourogenic $14-3-3-\xi$-isoform in a number of cancer cell types (Kumar et al. 2003). The pro-tumourogenic $14-3-3-\xi$-isoform is also overexpressed in Echincoccus metacestodes (Siles-Lucas and Gottstein, 2003), and the exposure of 2-ME $(2-10 \mu \mathrm{M})$ to $E$. multilocularis metacestodes in vitro severely damaged them in a dose-dependent manner. In parallel, drug treatment also down-scaled 14-3-3 transcription compared with actin expression (Naguleswaran et al. unpublished findings). Although it is not known how 2-ME exerts its effects on Echinococcus, the mechanism of action of 2-ME in cancer cells has been attributed to an interference with microtubule stability and a disregulation of the hypoxia-inducible factor (Klauber et al. 1997; Mabjeesh et al. 2003) inducing cancers cells to undergo apoptosis via extrinsic and intrinsic pathways.

\section{(iii) The Echinococcus signalling machinery as a novel drug target}

More recently, the excellent work of Brehm et al. (2006) has shed light on the factors involved in hostparasite communication in AE. E. multilocularis metacestodes express a number of developmental 
factors which they share with other metazoans. These include signalling systems which employ receptor tyrosine kinases of the epidermal growth factor (EGF, Spiliotis et al. 2003, 2006), the insulin/ insulin-like growth factor (Ins/IGF)-receptor families (Konrad et al. 2003) and the surface serine/ threonine kinases of the closely-related transforming growth factor-beta (TGF- $\beta$ ) and bone morphogenetic protein (BMP)-receptor families (ZavaloGongora et al. 2006). A cytokine of E. multilocularis which has significant homology to mammalian EGF is substantially upregulated in metacestodes cultured under conditions that promote growth and differentiation (Spiliotis et al. 2003). Also, EmSkip, a novel member of the SNW/SKIP family of transcriptional co-regulators was shown to be expressed in the Echinococcus metacestodes (including protoscoleces) during an infection of the intermediate host (Gelmedin et al. 2005). EmSkip interacts with EmSmadA and EmSmadB, two TGF- $\beta / \mathrm{BMP}$ signal transducers of $E$. multilocularis (see ZavaloGongora et al. 2003), indicating a role for this protein in TGF- $\beta$ signalling processes in this parasite. In addition, the downstream signalling elements of the MAP kinase cascade have been identified and characterized (Spiliotis and Brehm, 2004; Spiliotis et al. 2005, 2006). The Echinococcus MAP kinase cascade factors share molecular similarities to, but also differ in particular aspects from, their mammalian counterparts, and thus represent prime candidate targets for the development of novel anthelminthic drugs. This has been further substantiated via analysis of receptor activation, which has shown that the $E$. multilocularis insulin receptor EmIR interacts readily with insulin from the host, and TGF- $\beta$ receptor EmTR1 and possibly also the EGF-receptor EmER can interact with their corresponding host ligands (reviewed by Brehm et al. 2006). Thus, parasite and host have evolved means of communication that would largely influence the developmental biology of both parasite and host. The evidence indicates that these receptor-ligand systems play a central role in host-parasite interaction processes and thus represent interesting drug targets (Brehm et al. 2006). Cancer research has generated an enormous number of compounds which interfere with the functional activities of homologuous receptors or respective downstream kinases (see Sioud and Leirdal, 2007), and it will be the challenge now to identify drugs, or derivatives, which inhibit these receptors or the corresponding downstream enzymes in a parasite-specific manner.

\section{(iv) In silico approaches}

Mathis et al. (2005) employed current genomic sequence information to define a drug target in Echinococcus in silico, and subsequently confirmed their hypothesis experimentally. In bacteria, the ribosomes are important antibiotic targets, and macrolides such as erythromycin and clarithromycin are agents which bind to the nascent peptide exit tunnel near the peptidyltransferase centre of large subunit ribosomal RNA (rRNA) (RodriguezFonseca et al. 1995). Higher eukaryotes carry a guanine at position 2058 of both cytoplasmic and mitochondrial rRNAs, and this modification at this position has been demonstrated to confer the resistance of eukaryotic cells to macrolide antibiotics. In contrast, the mitochondrial rRNA of E. multilocularis carries an adenine at sequence position 2058, which would be predictive for susceptibility (Sander et al. 1997), while the nucleus-encoded rRNA is characterized by a guanine at 2058 (Mathis et al. 2005). Upon in vitro culture of $E$. multilocularis metacestodes with clarithromycin, parasites, as expected, exhibited severely impaired growth characteristics, presented morphologically altered mitochondria and displayed a lack of microtriches, all in a dose-dependent manner. Adult worms were also severely affected, lost their motility and displayed morphological alterations, such as shortening and constriction of proglottids and increased vacuolization. Mathis et al. (2005) were the first workers to employ a sequence-based in silico approach for the exploration of drugs whose mode of action was well studied at the molecular level and whose corresponding target was precisely defined. However, a prerequisite for such an approach is the availability of comprehensive genome sequence information for Echinococcus species.

\section{CONCLUDING REMARKS}

As outlined in this review, considerable efforts have been made to improve the therapeutical options for the treatment of $\mathrm{CE}$ and $\mathrm{AE}$. The benzimidazolebased treatment regimens have improved considerably the prognosis of patients but, due to the obvious setbacks, new developments are needed. Compounds that not only act as parastostatics but also as parasitocidals in vivo have not been discovered to date, but it is conceivable that such compounds actually exist. Thus, the current situation for affected patients is far from satisfactory. Academic institutions can provide a scientific basis that could eventually lead to novel treatment options, but financial constraints constantly limit the further development of promising avenues. Thus, considerably more input and support is needed from the pharmaceutical and biotechnological industries as well as governmental agencies to provide solutions for these neglected diseases. The novel genomic resources developing the discovery of the receptor-ligand interactions and associated signalling pathways which influence the parasite-host interaction, and the further characterization of immuno-modulatory molecules provide 
new and exciting opportunities and promising targets for future studies of novel chemotherapeutical and immuno-therapeutical options for $\mathrm{CE}$ and $\mathrm{AE}$.

We apologize to those authors whose contributions could not be cited in this paper. Norbert Mueller (Institute of Parasitology, University of Berne) is acknowledged for his great support and helpful comments. This work was supported through the National Science Foundation (31-111780), the Novartis Research Foundation, and the Swiss Secretariat for Ecudation and Science (grant No. C03.0007). M. Walker was a visiting scientist at Harvard School of Public Health, supported by an NSF fellowship.

\section{REFERENCES}

Ali-Khan, Z., Siboo, R., Gomersall, M. and Faucher, M. (1983). Cystolytic events and the possible role of germinal cells in metastasis in chronic alveolar hydatidosis. Annals of Tropical Medicine and Parasitology 77, 497-512.

Ammann, R. and Eckert, J. (1995). Clinical diagnosis and treatment of echinococcosis in humans. In Echinococcosis and Hydatid Disease (ed. Thompson, R. C. A. and Lymbery, A. J.), pp. 411-430. CAB International, Wallingford, UK.

Bartholomot, G., Vuitton, D. A., Harraga, S., Shi, D. Z., Giraudoux, P., Barnish, G., Wang, Y. H., MacPherson, C. N. and Craig, P. S. (2002). Combined ultrasound and serologic screening for hepatic alveolar echinococcosis in central China. American Fournal for Tropical Medicine and Hygiene 66, 23-29.

Baz, A., Ettlin, G. M. and Dematteis, S. (2006). Complexity and function of cytokine responses in experimental infection by Echinococcus granulosus. Immunobiology 211, 3-9.

Blanton, R. E., Wachira, T. M., Zeyhle, E., Njoroge, E. M., Magambo, J. K. and Schantz, P. M. (1998). Oxfendazole treatment of cystic hydatid disease in naturally infected animals. Antimicrobial Agents and Chemotherapy 42, 601-605.

Brehm, K., Kronthaler, K., Jura, H. and Frosch, M. (2000). Cloning and characterization of beta-tubulin genes from Echinococcus multilocularis. Molecular and Biochemical Parasitolology 107, 297-302.

Brehm, K., Spiliotis, M., Zavala-Gongora, R., Konrad, C. and Frosch, M. (2006). The molecular mechanisms of larval cestode development: first steps into an unknown world. Parasitology International 55, S15-S21.

Bresson-Hadni, S., Laplante, J. J., Lenys, D., Rohmer, P., Gottstein, B., Jacquier, P., Mercet, P., Meyer, J. P., Miguet, J. P. and Vuitton, D. A. (1994). Sero-epidemiologic screening of Echinococcus multilocularis infection in a European area endemic for alveolar echinococcosis. American Fournal of Tropical Medicine and Hygiene 51, 837-846.

Brunetti, E., Troia, G., Garlaschelli, A. L., Gulizia, R. and Filice, C. (2004). Twenty years of percutaneous treatments for cystic echinococcosis: a preliminary assessment of their use and safety. Parassitologia 46, $367-370$.
Casado, N., Urrea-Paris, M. A., Moreno, M. J., and Rodriguez-Caabeiro, F. (2001). Combined praziquantel and albendazole chemoprophylaxis in experimental hydatidosis. Parasitology Research 87, 787-789.

Chai, J., Menghebat, Wie, J., Deyu, S., Bin, L., Jincao, S., Chen, F., Xiong, L., Yiding, M., Xiuling, W., Dolikun, Guliber, Yanchun, W., Fanghua, G. and Shuhua, X. (2004). Observations on clinical efficacy of albendazole emulsion in 264 cases of hepatic cystic echinococcosis. Parasitology International 53, 3-10.

Cobo, F., Yarnoz, C., Sesma, B., Fraile, P., Aizcorbe, M., Trujillo, R., Diaz-de-Liano, A. and Ciga, M. A. (1998). Albendazole plus praziquantel versus albendazole alone as preoperative treatment in intraabdominal hydatidosis caused by Echinococcus granulosus. Tropical Medicine and International Health 3, 462-466.

Craig, P. (2003). Echinococcus multilocularis. Current Opinion in Infectious Diseases 16, 437-444.

Dai, W. J., Hemphill, A., Waldvogel, A., Ingold, K., Deplazes, P., Mossmann, $H$. and Gottstein, $B$. (2001). Major carbohydrate antigen of Echinococcus multilocularis induces an immunoglobulin $\mathrm{G}$ response independent of alpha beta $(+) \mathrm{CD} 4(+) \mathrm{T}$ cells. Infection and Immunity 69, 6074-6083.

Dai, W. J., Waldvoge1, A., Siles-Lucas, M. and Gottstein, B. (2004). Echinococcus multilocularis proliferation in mice and respective parasite 14-3-3 gene expression is mainly controlled by an alphabeta CD4 Tcell-mediated immune response. Immunology 112, 481-488.

Dakora, F. D. and Phillips, D. A. (1996). Diverse functions of isoflavonoids in legumes transcend antimicrobial definitions of phytoalexins. Physiological and Molecular Plant Pathology 49, 1-20.

Dematteis, S., Pirotto, F., Marques, J., Nieto, A., Orn, A. and Baz, A. (2001). Modulation of the cellular immune response by a carbohydrate rich fraction from Echinococcus granulosus protoscoleces in infected or immunized Balb/c mice. Parasite Immunology 23, $1-9$.

Dematteis, S., Rottenberg, M. and Baz, A. (2003). Cytokine response and outcome of infection depends on the infective dose of parasites in experimental infection by Echinococcus granulosus. Parasite Immunology 25, 189-197.

Diaz, A., Irigoin, R., Ferreira, F. and Sim, R. B. (1999). Control of host complement activation by the Echinococcus granulosus hydatid cyst. Immunopharmacology 42, 91-98.

Dueger, E. L., Moro, P. L. and Gilman, R. H. (1999). Oxfendazole treatment of sheep with naturally acquired hydatid disease. Antimicrobial Agents and Chemotherapy 43, 2263-2267.

Eckert, J. and Deplazes, P. (2004). Biological, epidemiological, and clinical aspects of echinococcosis, a zoonosis of increasing concern. Clinical Microbiology Reviews 17, 107-135.

Eckert, J., Thompson, R. C. A. and Mehlhorn, H. (1983). Proliferation and metastases formation of larval Echinococcus multilocularis. I. Animal model, macroscopical and histological findings. Zeitschrift für Parasitenkunde 69, 737-748. 
El-On, J. (2002). Benzimidazole treatment of cystic echinococcosis. Acta Tropica 85, 243-252.

Emery, I., Leclerc, C., Sengphommachanh, K., Vuitton, D. A. and Liance, M. (1998). In vivo treatment with recombinant IL-12 protects C57BL/6 mice against secondary alveolar echinococcosis. Parasite Immunology 20, 81-91.

Esposito, M., Mueller, N. and Hemphill, A. (2007). Structure-activity relationships from in vitro efficacies of the thiazolide series against the intracellular apicomplexan protozoan Neospora caninum. International Fournal for Parasitology 37, 183-190.

Ferreira, A. M., Irigoin, F., Breijo, M., Sim, R. B. and Diaz, A. (2000). How Echinococcus granulosus deals with complement. Parasitology Today 16, 168-172.

Ferreira, A. M., Diaz, A., Fernandez, C. and Sim, R. B. (2001). Assessment of in vivo complement activation on the Echinococcus granulosus hydatid cyst wall. Parasite Immunology 23, 655-658.

Fraize, M., Sarciron, M. E., Azzouz, S., Issadi, N., Bosquet, G. and Petavy, A. F. (2005).

Immunogenicity of two Echinococcus granulosus antigens EgA31 and EgTrp in mice. Parasitology Research 96, 113-120.

Frayha, G. J., Bikhazi, K. J. and Kachachi, T. A. (1981). Treatment of hydatid cysts (Echinococcus granulosus) by Cetrimide. Transactions of the Royal Society of Tropical Medicine and Hygiene 75, 447-450.

Garcia-Llamazares, J. L., Alvarez-de-Felipe, A. I., Redondo-Cardena, P., Voces-Alonso, J. A. and Prieto-Fernandez, J. G. (1997). In vivo inhibition of the regenerative capacity of hydatid material after treatment with netobimin. Parasitology Research 83, 105-108.

Gelmedin, V., Zavala-Gongora, R., Fernandez, C. and Brehm, K. (2005). Echinococcus multilocularis: cloning and characterization of a member of the SNW/ SKIP family of transcriptional coregulators. Experimental Parasitology 111, 115-120.

Godot, V., Harraga, S., Podoprigora, G., Liance, M., Bardonnet, K. and Vuitton, D. A. (2003). IFN-a-2a protects mice against helminth infection of the liver and modulates immune responses. Gastroenterology 124, 1441-1450.

Gottstein, B., Dai, W. J., Walker, M., Stettler, M., Muller, N. and Hemphill, A. (2002). An intact laminated layer is important for the establishment of secondary Echinococcus multilocularis infection. Parasitology Research 88, 822-828.

Gottstein, B., Haag, K., Walker, M., Matsumoto, J., Mejri, N. and Hemphill, A. (2006). Molecular survival strategies of Echinococcus multilocularis in the murine host. Parasitology International 55, S45-S49.

Gottstein, B. and Hemphill, A. (1997).

Immunopathology of echinococcosis. Chemical Immunology 66, 177-208.

Grenard, P., Bresson-Hadni, S., El Alaoui, S., Chevallier, M., Vuitton, D. A. and Ricard-Blum, S. (2001). Transglutaminase-mediated crosslinking is involved in the stabilization of extracellular matrix in human liver fibrosis. Fournal of Hepatology 35, 367-375.

Harraga, S., Godot, V., Bresson-Hadni, S., Pater, C., Beurton, I., Bartholomot, B. and Vuitton, D. A.
(1999). Clinical efficacy of and switch from T helper 2 to $\mathrm{T}$ helper 1 cytokine profile after interferon alpha2a monotherapy for human echinococcosis. Clinical Infectious Diseases 29, 205-206.

Hemphill, A., Mueller, J. and Esposito, M. (2006). Nitazoxanide, a broad-spectrum thiazolide antiinfective agent for the treatment of gastrointestinal infections. Expert Opinion in Pharmacotherapy 7, 953-964.

Hemphill, A., Stettler, M., Walker, M., Siles-Lucas, M., Fink, R. and Gottstein, B. (2002). Culture of Echinococcus multilocularis metacestodes; an alternative to animal use. Trends in Parasitology 18, 445-449.

Horton, R. J. (1989). Chemotherapy of Echinococcus infection in man with albendazole. Transactions of the Royal Society of Tropical Medicine and Hygiene 83, 97-102.

Horton, R. J. (1997). Albendazole in the treatment of human cystic echinococcosis: 12 years of experience. Acta Tropica 64, 79-93.

Hurd, H., Mackenzie, K. S. and Chappell, L. H. (1993). Anthelmintic effects of cyclosporin A on protoscoleces and secondary hydatid cysts of Echinococcus granulosus in the mouse. International Fournal for Parasitology 23, 315-320.

Jenne, L., Kilwinski, J., Radloff, P., Flick, W. and Kern, P. (1998). Clinical efficacy of immunologic alterations caused by interferon gamma therapy for alveolar echinococcosis. Clinical Infectious Diseases 26, 492-494.

Kern, P. (2003). Echinococcus granulosus infection: clinical presentation, medical treatment and outcome. Langenbecks Archives of Surgery 388, 413-420.

Kern, P. (2006). Medical treatment of echinococcosis under the guidance of Good Clinical Practice (GCP/ ICH). Parasitology International 55 (Suppl.), S273-S282.

Klauber, N., Parangi, S., Flynn, E., Hamel, E. and D'Amato, R. J. (1997). Inhibition of angiogenesis and breast cancer in mice by the microtubule inhibitors 2-methoxyestradiol and taxol. Cancer Research 57, $81-86$.

Klinkert, M. Q. and Heussler, V. (2006). The use of anticancer drugs in antiparasitic chemotherapy. Mini Reviews in Medicinal Chemistry 6, 131-143.

Konrad, C., Kroner, A., Spiliotis, M., ZavalaGongora, R. and Brehm, K. (2003). Identification and molecular characterisation of a gene encoding a member of the insulin receptor family in Echinococcus multilocularis. International fournal for Parasitology 33, 301-312.

Kumar, A. P., Garcia, G. E., Orsborn, J., Levin, V. A., and Slaga, T. J. (2003). 2-Methoxyestradiol interferes with $\mathrm{NfkB}$ transcriptional activity in primitive neuroectodermal brain tumours: implications for management. Carcinogenesis 24, 209-216.

Launchbury, A. P. and Habboubi, N. (1993). Epirubicin and doxorubicin: a comparison of their characteristics, therapeutic activity and toxicity. Cancer Treatment Reviews 19, 197-228.

Lawton, P., Walchshofer, N. and Sarciron, M. E. (2001). In vitro effects of isoprinosine and a dipeptide methyl ester on Echinococcus multilocularis protoscoleces. Fournal of Helminthology 75, 251-257. 
Liance, M., Bresson-Hadni, S., Vuitton, D. A., Lenys, D., Carbillet, J. P. and Houin, R. (1992). Effects of cyclosporin A on the course of murine alveolar echinococcosis and on specific cellular and humoral immune responses against Echinococcus multilocularis. International Fournal for Parasitology 22, 23-28.

Liance, M., Nemati, F., Bories, C. and Couvreur, P. (1993). Experience with doxorubicin-bound polyisohexylcyanoacrylate nanoparticles on murine alveolar echinococcosis of the liver. International Fournal for Parasitology 23, 427-429.

Liance, M., Ricard-Blum, S., Emery, I., Houin, R. and Vuitton, D. A. (1998). Echinococcus multilocularis infection in mice: in vivo treatment with a low dose of IFN-gamma decreases metacestode grwoth and liver fibrogenesis. Parasite 5, 231-237.

Mabjeesh, N. J., Escuin, D., LaVallee, T. M., Pribluda, V. S., Swartz, G. M., Johnson, M. S., Willard, M. T., Zhong, H., Simons, J. W. and Giannakakou, P. (2003). 2-ME2 inhibits tumor growth and angiogenesis by disrupting microtubules and dysregulating HIF. Cancer Cell 3, 363-375.

MacPherson, C. N., Kachani, M., Lyagoubi, M., Berrada, M., Shepherd, M., Fields, P. F. and El Hasnaoui, M. (2004). Cystic echinococcosis in the Berber of the Mid Atlas mountains, Morocco: new insights into the natural history of the disease in humans. Annals of Tropical Medicine and Parasitology 98, 481-490.

Maizels, R. M. and Yazdanbakhsh, M. (2003). Immune regulation by helminth parasites: Cellular and molecular mechanisms. Nature Reviews Immunology $\mathbf{3}$, 733-744.

Manfras, B., Reuter, S., Wendland, T. and Kern, P. (2002). Increased activation and oligoclonality of peripheral CD8 $+\mathrm{T}$ cells in the chronic human helminth infection alveolar echinococcosis. Infection and Immunity 70, 1168-1174.

Martinez, J., Perez-Serrano, J., Bernadina, W. E. and Rodriguez-Caabeiro, F. (1999). Echinococcus granulosus: in vivo effects of ivermectin and praziquantel on hsp60 and hsp70 levels. Experimental Parasitology 93, 171-180.

Marchiondo, A. A., Ming, R., Andersen, F. L., Slusser, J. H. and Conder, G. A. (1994). Enhanced larval cyst growth of Echinococcus multilocularis in praziquantel-treated jirds (Meriones unguiculatus). American Fournal of Tropical Medicine and Hygiene 50, 120-127.

Mathis, A., Wild, P., Boettger, E. C., Kapel, C. M. O. and Deplazes, P. (2005). Mitochondrial ribosome as the target for the macrolide antibiotic clarithromycin in the helminth Echinococus multilocularis. Antimcirobial Agents and Chemotherapy 49, 3251-3255.

McManus, D. P., Wenbao, Z., Jun, L. and Bartley, P. B. (2003). Echinococcosis. The Lancet 362, 1295-1304.

Mehlhorn, H., Eckert, J., and Thompson, R. C. A. (1983). Proliferation and metastases formation of larval Echinococcus multilocularis II. Ultrastructural investigations. Zeitschrift für Parasitenkunde 69, $749-763$
Messina, M. Soy, soy phytoestrogens (isoflavones), and breast cancer. American Fournal of Clinical Nutrition 70, 574-575.

Miyaji, S., Katakura, K., Matsufuji, S., Murakami, Y., Hayashi, S., Oku, Y., Okamoto, M. and Kamiya, M. (1993). Failure of treatment with alpha-difluoromethylornithine against secondary multilocular echinococcosis in mice. Parasitology Research 79, 75-76.

Moro, P. L., Garcia, H. H., Gonzales, A. E., Bonilla, J. J., Verastegui, M. and Gilmanmd, R. H. (2005). Screening for cystic echinococcosis in an endemic region of Peru using portable ultrasonography and the enzyme linked immunoelectrotransfer blot (EITB) assay. Parasitology Research 96, 242-246.

Morris, D. L., and Taylor, D. H. (1990). Echinococcus granulosus: development of resistance to albendazole in an animal model. Fournal of Helminthology 64, 171-174.

Naguleswaran, A., Spicher, M., Vonlaufen, N., Ortega-Mora, L. M., Torgerson, P., Gottstein, B. and Hemphill, A. (2006). In vitro metacestodicidal activities of genistein and other isoflavones against Echinococcus multilocularis and Echinococcus granulosus. Antimicrobial Agents and Chemotherapy 50, 3770-3778.

Ohbayashi, M., Rausch, R. L. and Fay, F. H. (1971). On the ecology and distribution of Echinococcus spp. (Cestoda: Taeniidae), and characteristics of their development in the intermediate host. II. Comparative studies on the larval E. multilocularis Leuckart, 1863, in the intermediate host. Fapanese Fournal of Veterinary Research, 19, 1-9.

Ortona, E., Margutti, P., Delunardo, F., Vaccari, S., Rigano, R., Profumo, E., Buttari, B., Teggi, A. and Siracusano, A. (2003). Molecular and immunological characterization of the $\mathrm{C}$-terminal region of a new Echinococcus granulosus heat shock protein 70. Parasite Immunology 25, 119-126.

Pawloski, Z. S. (1997). Critical points in the clinical management of cystid echinococcosis: a revised review. In Compendium on Cystic Echinococcosis (ed. Anderson, F. L., Ouhelli, H. and Kachani, M.), pp. 119-135. Brigham Young University, Provo, USA.

Pawloski, Z. S., Eckert, J., Vuitton, D. A., Ammann, R. W., Kern, P., Craig, P. S., Dar, K. F., De Rosa, F., Filice, C., Gottstein, B., Grimm, F., MacPhearson, C. N. L., Sato, N., Todorov, T., Uchino, J., von Sinner, W. and Wen, H. (2001). Echinococcosis in humans: clinical aspects, diagnosis and treatment. In WHO/OIE Manual on Echinococcosis in Humans and Animals : a Public Health Problem of Global Concern (ed. Eckert, J., Gemmell, M. A., Meslin, F. X. and Pawlowski, Z. S), pp. 20-32. World Organization for Animal Health and World Health Organization, Paris, France.

Rau, M. E. and Tanner, C. E. (1975). BCG suppresses growth and metastasis of hydatid infections. Nature, London 256, 318-319.

Rausch, R. L., Wilson, J. F., Schantz, P. M. and McMahon, B. J. (1987). Spontaneous death of Echinococcus multilocularis: case diagnosised serologically (by Em2-Elisa) and clinical significance. American Fournal of Tropical Medicine and Hygiene 36, 576-585. 
Rausch, R. L. (1995). Life cycle patterns and geographic distribution of Echinococcus species. In Echinococcosis and Hydatid Disease (ed. Thompson, R. C. A. and Lymbery, A. J.), pp. 89-99. CAB International, Wallingford, UK.

Reuter, S., Buck, A., Grebe, O., Nüssle-Kügele, K., Kern, P. and Manfras, B. (2003b). Salvage treatment with amphotericin B in progressive human alveolar echinococcosis. Antimicrobial Agents and Chemotherapy 47, 3586-3591.

Reuter, S., Buck, A., Manfras, B., Kratzer, W., Seitz, H. M., Darge, K., Reske, S. N. and Kern, P. (2004). Structured treatment interuption in patients with alveolar echinococcosis. Hepatology 39, 509-517.

Reuter, S., Jensen, B., Buttenschoen, K., Kratzer, W. and Kern, P. (2000). Benzimidazoles in the treatment of alveolar echinococcosis. Fournal of Antimicrobial Chemotherapy 46, 451-460.

Reuter, S., Manfras, B., Merkle, M., Harter, G. and Kern, P. (2006). In vitro activities of itraconazole, methiazole, and nitazoxanide versus Echinococcus multilocularis larvae. Antimicrobial Agents and Chemotherapy 50, 2966-2970.

Reuter, S., Merkle, M., Brehm, K., Kern, P. and Manfras, B. $(2003 a)$. Effect of amphotericin B on larval growth of Echinococcus multilocularis. Antimicrobial Agents and Chemotherapy 47, 620-625.

Reynaud, J., Guilet, D., Terreux, R., Lussignol, $M$. and Walchshofer, N. (2005). Isoflavonoids in nonleguminous families: an update. Natural Products Reports 22, 504-515.

Rigano, R., Profumo, E., Ioppolo, S., Notargiacomo, S., Ortona, E., Teggi, A. and Siracusano, A. (1995). Immunological markers indicating the effectiveness of pharmacological treatment in human hydatid disease. Clinical Experimental Immunology 102, 281-285.

Rigano, R., Buttari, B., De Falco, E., Profumo, E., Ortana, E., Margutti, P., Scotta, C., Teggi, A. and Siracusano, A. (2004). Echinococcus granulosus-specific $\mathrm{T}$ cell lines derived from patients at various clinical stages of cystic echinococcosis. Parasite Immunology 26, 45-52.

Rodrigues, J. M., Bories, C., Emery, I., Fessi, H., Devissaguet, J. P. and Liance, M. (1995).

Development of an injectable formulation of albendazole and in vivo evaluation of its efficacy against Echinococcus metacestodoe. International Fournal for Parasitology 25, 1437.

Rodriguez-Fonseca, C., Amils, R. and Garret, R. A. (1995). Fine structure of the peptidyl transferase centre on 23S-like rRNAs deduced from chemical probing of antibiotic ribosome complexes. Fournal of Molecular Biology 27, 224-235.

Rogan, M. T. and Richards, K. S. (1986). Echinococcus granulosus: in vivo effect of monensin on the tegument of the protoscolex. Parasitology 93, 347-355.

Sander, P. T., Prammananan, T., Meier, A., Frischkorn, K. and Bottger, E. C. (1997). The role of ribosomal RNAs in macrolide resistance. Molecular Microbiology 26, 469-480.

Sarciron, M. E., Delabre, I., Walbaum, S., Raynaud, G., and Petavy, A. F. (1992). Effects of multiple doses of isoprinosine on Echinococcus multilocularis metacestodes. Antimicrobial Agents and Chemotherapy 36, 191-194.

Sarciron, M. E., Walbaum, S., Arsac, C., Raynaud, G., and Petavy, A. F. (1993). Echinococcus granulosus: isoprinosine treatment of the metacestode stage. American Fournal of Tropical Medicine and Hygiene 48, 658-665.

Sarciron, M. E., Walbaum, M. E. and Petavy, A. F. (1995). Effects of Isoprinosine on Echinococcus multilocularis and E. granulosus metacestodes. Parasitology Research 81, 329-333.

Sarciron, M. E., Walchshofer, N., Walbaum, S., Arsac, C., Descotes, J., Petavy, A. F. and Paris, J. (1997). Increases in the effects of albendazole on Echinococcus multilocularis metacestodes by the dipeptide methyl ester (Phe-Phe-OMe). American Fournal of Tropical Medicine and Hygiene 56, 226-230.

Schantz, P. M., Chai, J., Craig, P. S., Eckert, J., Jenkins, D. J., Macpherson, C. N. L. and Thakur, A. (1995). Epidemiology and control of hydatid disease. In Echinococcosis and Hydatid Disease (ed. Thompson, R. C. A. and Lymbery, A. J.), pp. 233-245. CAB International, Wallingford, UK.

Schmid, M., Samonigg, H., Stoger, H, Auer, H., Sternthal, M. H., Wilders-Truschnig, $M$. and Reisinger, E. C. (1995). Use of interferon-gamma and mebendazole to stop the protression of alveolar hydatid disease: case report. Clinical Infectious Diseases 20, 1543-1546.

Schumacher, G. and Neuhaus, P. (2001). The physiological estrogen metabolite 2-methoxyestradiol reduces tumor growth and induces apoptosis in human solid tumors. Fournal of Cancer Research and Clinical Oncology 127, 405-410.

Siles-Lucas, M., Felleisen, R. S., Hemphill, A., Wilson, W. and Gottstein, B. (1998). Stage-specific expression of the 14-3-3 gene in Echinococcus multilocularis. Molecular and Biochemical Parasitolology 91, 281-293.

Siles-Lucas, M. and Gottstein, B. (2003). The 14-3-3 protein: a key molecule in parasites as in other organisms. Trends in Parasitology 19, 575-581.

Siles-Lucas, M. and Hemphill, A. (2002). Cestode parasites: Application of in vivo and in vivo models for studies on the host-parasite relationship. Advances in Parasitology 51, 133-230.

Siles-Lucas, M., Nunes, C. P. and Zaha, A. (2001). Comparative analysis of the 14-3-3 gene and its expression in Echinococcus granulosus and Echinococcus multilocularis metacestodes. Parasitology 122, 281-287.

Sioud, M. and Leirdal, M. (2007). Druggable signaling proteins. Methods in Molecular Biology 361, 1-24.

Spiliotis, M. and Brehm, K. (2004). Echinococcus multilocularis: identification and molecular characterization of a Ral-like small GTP-binding protein. Experimental Parasitology 107, 163-172.

Spiliotis, M., Konrad, C., Gelmedin, V., Tappe, D., Bruckner, S., Mosch, H. U. and Brehm, K. (2006). Characterisation of EmMPK1, an ERK-like MAP kinase from Echinococcus multilocularis which is activated in response to human epidermal growth factor. International Fournal for Parasitology 36, 1097-1112.

Spiliotis, M, Kroner, A. and Brehm, K. (2003).

Identification, molecular characterization and 
expression of the gene encoding the epidermal growth factor receptor orthologue from the fox-tapeworm Echinococcus multilocularis. Gene 323, 57-65.

Spiliotis, M., Tappe, D., Bruckner, S., Mosch, H. U. and Brehm, K. (2005). Molecular cloning and characterization of Ras- and Raf-homologues from the fox-tapeworm Echinococcus multilocularis. Molecular and Biochemical Parasitology 139, 225-237.

Spiliotis, M., Tappe, D., Sesterhenn, L. and Brehm, K. (2004). Long-term in vitro cultivation of Echinococcus multilocularis metacestodes under axenic conditions. Parasitology Research 92, 430-432.

Stettler, M., Fink, R., Walker, M., Gottstein, B., Geary, T. G., Rossignol, J. F. and Hemphill, A. (2003). In vivo parasiticidal effect of nitazoxanide against Echinococcus multilocularis metacestodes. Antimicrobial Agents and Chemotherapy 47, 467-474.

Stettler, M., Rossignol, J. F., Fink, R., Walker, M., Gottstein, B., Merli, M., Theurillat, R., Thormann, W., Dricot, E., Segers, R. and Hemphill, A. (2004). Secondary and primary murine alveolar echinococcosis: combined albendazole/nitazoxanide chemotherapy exhibits profound anti-parasitic activity. International Fournal for Parasitology 34, 615-624.

Stey, C. and Jost, R. (1993). Rezidivierende, lebensbedroliche Anaphylaxie als Erstmanifestation eines Echinococcus cysticus (granulosus) der Leber. Schweizerische Medizinische Wochenzeitschrift, 123, 1445-1450.

Taylor, D. H., Richards, K. S. and Morris, D. L. (1989). Rapid recovery of Echinococcus granulosus following 'successful' albendazole therapy in a gerbil model. Fournal of Helminthology 63, 349-352.

Thompson, R. C. A. (1986). Biology and systematics of Echinococcus. In The Biology of Echinococcus and Hydatid Disease (ed. Thompson, R. C. A.), pp. 5-17. Allen and Unwin, London.

Torgerson, P. R. (2003). Economic effects of echinococcosis. Acta Tropica 85, 113-118.

Urrea-Paris, M. A., Casado, N., Moreno, M. J. and Rodriguez-Caabeiro, F. (2001). Chemoprophylactic praziquantel treatment in experimental hydatidosis. Parasitology Research 87, 510-512.

Urrea-Paris, M. A., Moreno, M. J., Casado, N. and Rodriguez-Caabeiro, F. (1999). Echinococcus granulosus: praziquantel treatment against the metacestode stage. Parasitology Research 85, 999-1006.

Vuitton, D. A., Bresson-Hadni, S., Laroche, L., Kaiserlian, D., Guerret-Stocker, S., Bresson, J. L. and Gilbert, M. (1989). Cellular immune response in Echinococcus multilocularis infection in humans. II. Natural killer cell activity and cell subpopulations in the blood and in the periparasitic granuloma of patients with alveolar echinococcosis. Clinical and Experimental Immunology 78, 67-74.

Vuitton, D. A., Zhang, S. L., Yang, Y., Godot, V., Beurton, I., Mantion, G., Bresson-Hadni, S. (2006). Survival strategy of Echinococcus multilocularis in the human host. Parasite International 55, S51-S55.

Walchshofer, N., Delabre-Defayolle, I., Paris, J. and Petavy, A. F. (1990). In vivo morphological damage induced by a new benzimidazole pro-drug in Echinococcus multilocularis metacestodes. Fournal of Pharmacological Science 79, 606-608.

Walker, M., Baz, A., Dematteis, S., Stettler, M., Gottstein, B., Schaller, J. and Hemphill, A. (2004a). Isolation and characterization of a secretory component of Echinococcus multilocularis metacestodes potentially involved in modulating the host-parasite interface. Infection and Immunity 72, 527-536.

Walker, M., Rossignol, J. F., Torgerson, P. and Hemphill, A. $(2004 b)$. In vivo effects of nitazoxanide on Echinococcus granulosus protoscoleces and metacestodes. Fournal of Antimicrobial Chemotherapy 54, 609-616.

Wangoo, A., Ganguly, N. K. and Mahajan, R. C. (1987). In vivo efficacy of mebendazole in containment of larval cyst mass in early stages of hydatid disease due to Echinococcus granulosus. Transactions of the Royal Society of Tropical Medicine and Hygiene 81, 965-966.

Wen, H., New, R. R., Muhmut, M., Wang, J. H., Wang, Y. H., Zhang, J. H., Shao, Y. M. and Craig, P. S. (1996). Pharmacology and efficacy of liposomeentrapped albendazole in experimental secondary alveolar echinococcosis and effect of co-administration with cimetidine. Parasitology 113, 111-121.

Xiao, S., Feng, J. and Yao, M. (1995). Effect of antihydatid drugs on carbohydrate metabolism of metacestode of Echinococcus granulosus. Chinese Medical Fournal 108, 682-688.

Zavala-Gongora, R., Kroner, A., Bernthaler, P., Knaus, P. and Brehm, K. (2006). A member of the transforming growth factor-beta receptor family from Echinococcus multilocularis is activated by human bone morphogenetic protein 2. Molecular and Biochemical Parasitology 146, 265-271.

Zavala-Gongora, R., Kroner, A., Wittek, B., Knaus, P. and Brehm, K. (2003). Identification and characterisation of two distinct Smad proteins from the fox-tapeworm Echinococcus multilocularis. International Fournal for Parasitology 33, 1665-1677.

Zhang, W. and McManus, D. P. (2006). Recent advances in the immunology and diagnosis of echinococcosis. FEMS Immunology and Medical Microbiology 47, 24-41. 